\title{
Mothers' Experiences of Having an Adolescent Child with Depression: An Interpretative Phenomenological Analysis
}

\author{
Sarah Armitage ${ }^{1} \cdot$ Monika Parkinson $\mathbb{1}^{2} \cdot$ Sarah Halligan ${ }^{3} \cdot$ Shirley Reynolds ${ }^{2}$
}

Published online: 2 March 2020

(c) The Author(s) 2020

\begin{abstract}
Objectives Adolescence represents a significant period of vulnerability for the development of depression. Whilst research has begun to explore factors associated with the development, maintenance and outcomes of adolescent depression, there is little research investigating this experience from a parental viewpoint. The aim of this study was to explore mothers' experiences of having an adolescent child with depression.

Methods Eight mothers of depressed adolescents were recruited following their child's clinical assessment at a Child and Adolescent Mental Health Service and participated in semi-structured interviews. The transcripts of the interviews were analysed using interpretative phenomenological analysis.

Results The analysis revealed five interlinked superordinate themes: Finding a reason, something to blame; Living with uncertainty; Feelings of helplessness and frustration; Depression causes change; Hiding own emotions and needs. A key finding across the themes was the emotional distress and sense of uncertainty experienced by the mothers.

Conclusions The findings highlight avenues for clinical practice and further research including exploring the type and format of information and support that parents would value most, the views of fathers, and more in-depth exploration of the identified themes with parents using both qualitative and quantitative methods.
\end{abstract}

Keywords Mother $\cdot$ Parenting $\cdot$ Adolescence $\cdot$ Depression $\cdot$ Interpretative phenomenological analysis (IPA)

\section{Highlights}

- Little is known about the parental experience of having a child with depression.

- Mothers' experiences were explored using interpretative phenomenological analysis.

- Mothers of depressed adolescents described self-blame, distress and uncertainty.

- Mothers experienced feelings of helplessness, frustration and subjugated own needs.

- There is a need for evidence-based and timely information and support for parents.

Adolescence is the period of life when individuals are at the highest risk of developing depression, with recent global

Monika Parkinson

m.b.parkinson@ reading.ac.uk

1 Oxford Institute of Clinical Psychology Training and Research, Isis Education Centre, Warneford Hospital, Headington, Oxford OX3 7JX, UK

2 School of Psychology and Clinical Language Sciences, University of Reading, Earley Gate, Reading RG6 6AL, UK

3 Department of Psychology, University of Bath, Bath BA2 7AY, UK prevalence rates of $2.6 \%$ (Polanczyk et al. 2015). Adolescent onset depression represents a major individual and social concern. It is linked with chronic and severe forms of depression and concurrent and long-term negative psychosocial consequences, including educational underachievement and unemployment (Fergusson and Woodward 2002; Glied and Pine 2002; Zisook et al. 2007). Personal accounts from young people highlight that depression is associated with significant distress and impacts negatively on social interactions, communication, and sense of identity (Midgley et al. 2015; Shaw et al. 2009).

Parenting an adolescent with a mental health problem presents considerable demands on parents (e.g. DeaterDeckard 2004). Parents typically report feelings of 
helplessness and powerlessness (e.g. Thomson et al. 2014), and strong emotions including shock, pain, guilt, shame, and fear (e.g. Oldershaw et al. 2008). Parents try to make sense of the changes they observe in their son or daughter (e.g. Thomson et al. 2014) and describe unmet needs for information and support (e.g. Raphael et al. 2006).

Parents of adolescents with depression report relatively higher levels of parenting stress, lower parent wellbeing (Deater-Deckard 2004; Early et al. 2002), lower parenting selfefficacy (Steca et al. 2011) and make more negative attributions for their child's behaviour than parents of non-depressed adolescents, even when adolescent behaviour is controlled for (Sheeber et al. 2009). Tan and Rey (2005) found that mothers of depressed adolescents tended to perceive their child as 'difficult' and experienced higher levels of parenting stress and low mood. These are important considerations given that it is suggested that there is a bi-directional influence between parental factors and adolescent depression (Garber 2005) and parental wellbeing has been shown to influence child and family outcomes (Early et al. 2002).

To maximise the potential impact that parents could have in supporting their son or daughter in treatment for depression and contributing to their recovery, it is important to understand their perspectives and experiences. Parents are often key in helping their children to access appropriate treatment for their difficulties (Zwaanswijk et al. 2005), to adhere and manage symptoms (Nock and Ferriter 2005) and in some treatment approaches their full engagement and involvement is an important part of the intervention (e.g. Diamond et al. 2010). Parents are also frequently involved by therapists to reinforce strategies from the adolescent's treatment sessions (e.g. Wells and Albano 2005) and may be helpfully included in safety planning where risk is an issue (e.g. Gryglewicz et al. 2018). Knowing more about parental perspectives can provide a better understanding of how to support them, so that parents can support their children during treatment. It may also inform us about how we can adjunct existing treatments with strategies that parents may find helpful for themselves.

Qualitative research can highlight shared and unique experiences of participants and may identify novel aspects of the experiences that are not captured by standardised quantitative measures (Willig 2008). Only two qualitative studies have considered the experience of depression in adolescents from the perspective of a parent. Draucker (2005) interviewed four parents of adolescents using a grounded theory approach. Their data suggested that the acknowledgment of adolescent depression within the family follows three stages. Firstly, adolescents, parents and professionals deny the problem and project a 'normal' image. Subsequently, adolescents begin to show distress and parents develop an awareness of this. Finally, the adolescent is open about their experience and amenable to receiving help. Stapley et al. (2015) used a semistructured interview to investigate the experiences of a heterogeneous group of 48 parents of adolescents aged 11-17 years. The adolescents had been diagnosed as having moderate to severe depression and were participants in a randomised controlled trial examining effectiveness of psychological therapies for depression (Goodyer et al. 2017). Their thematic analysis highlighted four main themes: parents' 'lack of awareness' that their child was experiencing any issues or depression; the 'emotional turmoil' that parents and children both struggled with; parental feelings of 'helplessness'; and 'parenting in overdrive'. As the parental interviews in this study were part of a battery of baseline assessments, the authors noted their relative brevity. Given that mothers tend to be most often engaged with health services used by their adolescent child (Page et al. 2008), a detailed examination of the mothers' perspectives in particular may highlight areas of specific importance and concern.

The aim of this study was to understand the experience of mothers who have an adolescent child recently diagnosed with depression. We used an interpretative phenomenological analysis (IPA) approach, which demands an in-depth interview, exploration and analysis, and allows for an understanding of what a group that has similar characteristics and shares a recent experience thinks and believes about their personal experiences (Smith et al. 2009). Within this study, the key similarity was being a mother of an adolescent with clinical depression recently diagnosed in a CAMH service, prior to treatment. The IPA methodology allows for new ideas and understandings about phenomena to emerge, over and above the detection of thematic patterns across participants. We specifically addressed the question 'What is it like to be the mother of an adolescent child who is experiencing depression?'

\section{Method}

\section{Participants}

Mothers whose adolescent (13-18 years old) child had been referred to a Child and Adolescent Mental Health Service (CAMHS) for depression were informed about the study. Diagnosis of primary depression was established through structured clinical assessments using the Schedule for Affective Disorders and Schizophrenia for School Aged Children (Puig-Antich and Chambers 1978).

As IPA requires individuals to be able to express their experiences in great detail (Smith et al. 2009), mothers were only eligible to take part if they were English speakers and did not have any significant communication or learning disabilities. Mothers were excluded if they did not currently 
live with their son or daughter or did not hold parental responsibility. Mothers were also excluded if their son or daughter had a learning disability or autistic spectrum disorder as depression can present differently in these groups (Hurley 2008; Stewart et al. 2006).

Just under half of the mothers invited took part. Those who did not take part cited other commitments $(n=8)$, or their child did not give assent $(n=2)$. Seven participants were White British, one was White South African. Four were single parents whose children had contact with their fathers, two lived with the father of the child and two were widows. Seven mothers reported a history of depression. The mothers differed in terms of their family circumstances (i.e. single parenthood and co-parenting) and their child's characteristics (i.e. one child had mild cerebral palsy). The majority $(n=7)$ of the participants were mothers of adolescent daughters with depression, one was a mother of an adolescent son. Half $(n=4)$ of the adolescents had a co-morbid anxiety disorder.

\section{Procedure}

Interview data were collected using a semi-structured schedule administered by a trainee clinical psychologist (SA). In all cases the interview was carried out before the child started treatment within CAMHS and shortly after the initial clinical assessment. The interviews lasted between 45 and $90 \mathrm{~min}$. The interviews were conducted in the participant's home $(n=5)$ and in CAMHS clinics $(n=3)$, depending on participant preference.

\section{Measures}

The interview schedule was designed to elicit mothers' thoughts, feelings and experiences associated with having an adolescent child with depression. The interview included the following broad areas and topics; what it was like as a family and parent before the start of the child's depression, the time during the onset of the depression, and experiences as a parent during the course of the child's depression. The interview schedule was used flexibly, with the interviewee directing the interview in the main, to explore those areas most salient to them (Smith et al. 2009).

\section{Data Analysis}

All interviews were transcribed by a professional typist. All identifying information was excluded or changed in order to protect participant confidentiality. Transcripts were analysed using IPA (Smith et al. 2009). IPA is a qualitative methodology which aims to 'give voice' (page 1) to participants' major life experiences and examine how they make sense of them (Larkin et al. 2006). IPA thus seeks to explore the internal perspectives of the participants' experiences (Smith 1996). It involves a detailed, line-by-line analysis of transcripts and an analysis of the meaning of each participant's experiences.

Transcripts were coded and analysed by the first author according to the principles of IPA (Smith et al. 2009). Each transcript was read and re-read (cases were analysed individually initially, then across multiple cases). Exploratory coding was completed, which consisted of identifying three principle types of data: descriptive information (use of words/phrases), linguistic features (noting the use of non-verbal expressions) and conceptual ideas (considering meaning). Emergent coding was developed by compiling any themes that seemed to capture the essence of the experience; patterns and differences were noted between codes. The initial themes were organised on a case by case basis and clustered into coherent wider themes. All cases were reviewed and their themes amalgamated, considering how themes relate to one another following an iterative process, the researcher repeatedly returned to the original transcripts to ground, validate and refine emerging themes. The identified themes were further refined into superordinate themes using supervision, and credibility checks and then presented in a written narrative account.

Quality control of the data analysis was enhanced through regular supervision with the second author (MP). During supervision, alternative potential interpretations of the data were carefully considered, and reflexive discussions held about researcher expectations to acknowledge and reduce the impact of researcher bias. Credibility checks were completed by the second author which involved cross-checking emergent themes. This involved the second author reviewing segments of the transcripts to ensure both the initial and later the final themes reflected the data. Reflexivity was emphasised throughout the research process (Willig 2008) and enhanced by using a reflective log. The first author was regularly interviewed by the second author and another IPA researcher to explore any pre-existing ideas and beliefs about parental experiences of adolescent depression. These interviews provided the opportunity to discuss the interpretations of the data and any personal biases throughout the process in an attempt to reduce their potential influence. Key themes identified through reflections included the power differential between the interviewer (who was perceived as a CAMHS professional) and the participant, the role of guilt and shame in the mothers' accounts, assumptions about the role of being a mother and beliefs about and experiences of NHS services that are provided for adolescents with depression.

All themes were checked by IPA researchers as part of an IPA researchers' group. One member of the group conducted a quality check of one transcript to check content and emerging themes and another group member checked the transcripts throughout the study. The second 
author also checked themes against the original transcripts. To further adhere to the philosophy and process of IPA, the first author attended an IPA training course, received consultation from an IPA expert, and regularly attended an IPA researchers' group.

\section{Results}

\section{Identified Themes}

Five superordinate themes were identified from data analysis, some with several subordinate themes. These are presented in Table 1.

\section{Finding a Reason, Something to Blame}

"You can lose your mind thinking why wondering where, if, how, what if" (Sophie).

The first superordinate theme encapsulates mothers' attempts to understand "how did we get to this?" (Emma); to find a source of blame for the child's depression, either internally or externally, or both.

\section{Blaming oneself: "if I was good at what I was doing,} we wouldn't be where we are now".

This prominent subordinate theme captured the mothers' perception that the depression may have occurred because they were "not a good enough parent" (Jackie). Mothers were concerned they had not achieved

Table 1 Superordinate and subordinate themes

\begin{tabular}{ll}
\hline Superordinate themes & Subordinate themes \\
\hline $\begin{array}{l}\text { Finding a reason, something } \\
\text { to blame }\end{array}$ & $\begin{array}{l}\text { Blaming oneself } \\
\text { Feeling blamed by others } \\
\text { Blaming external factors } \\
\text { Living with fear } \\
\text { The long-term impact of } \\
\text { depression }\end{array}$ \\
& $\begin{array}{l}\text { The unpredictability of the your } \\
\text { child's challenging behaviour }\end{array}$ \\
& $\begin{array}{l}\text { Adapting parenting } \\
\text { Not knowing how to help } \\
\text { Feelings of helplessness and }\end{array}$ \\
frustration & $\begin{array}{l}\text { Not knowing who can help } \\
\text { Depression causes change }\end{array}$ \\
& $\begin{array}{l}\text { Witnessing a change in personality } \\
\text { Change in family interactions }\end{array}$ \\
\end{tabular}

their "role" of "keeping them safe and making sure they're happy" (Jackie). All mothers in the interview questioned whether the depression was their "fault" (Mel), either as a result of their relationship situation, their own experience of depression and/or their parenting.

I was hoping that I, my mood hadn't influenced her (Emma).

As a separated mum you are feeling continuous guilt that you have ruined your children's lives (Jane).

Viv described feeling as if she were "failing" as a parent (Viv), displaying a sense of guilt and shame that her child had depression. A common response to self-blame was seeking reassurance either from their child or from friends and professionals; Emma explained she asked her daughter if she had "done anything to upset her" and Jane found it important to contact a counsellor to ask whether her actions would have caused the depression and felt absolved when "she said absolutely not". A number of mothers felt these feelings were common to all mothers, whether depression was a factor or not; these mothers appeared to appreciate that, from an objective standpoint, they had not caused their child's difficulties.

I think as a Mum you automatically feel guilty about everything, so I did (Emma).

Some mothers described a viewpoint of feeling guilty, whilst simultaneously knowing that it is not their fault.

I think with a lot of it you can feel guilty that it's all your fault but I know deep down it isn't (Emma).

Feeling blamed by others: "You sort of feel like you're being judged'.

Some mothers shared a sense that they were judged by others, and blamed for their children's difficulties. Alex, for example, recalls feeling "mortified" to find her child was depressed. Jackie explained that her daughter's self-harm and suicide attempt in particular caused her to feel judged as responsible for these behaviours.

It's not something I ever thought one of my children would do [...] Kids with problems do that [...] maybe they're judging us because maybe we're doing something (Jackie).

She explained that she does not feel others are, in all likelihood, actually judging her, but it nonetheless remains a concern. There appeared to be attempts by mothers to 
distance themselves from other parents who are not considered as caring towards their children, "we weren't like, some parents just drop them off at the class" (Alex), perhaps in order to illustrate their own attentiveness. Interestingly, there were numerous descriptions of what may be understood to be 'good' parenting and family life, for example, descriptions of "having meals together" (Jackie). It wasn't explicitly stated, but it could be speculated that this might have been in response to perceived judgement during the interviews.

\section{Blaming external factors: "Is she just hormonal? Is it just a teenage phase?”.}

The mothers mentioned other external explanations for the development of the depression in their attempts to make sense of its development. These varied from "a chemical imbalance" (Viv), to "something to do with our education system" (Jackie). This was an alternative view to the first subordinate theme, where mothers were directing the blame towards themselves. Jenny, the mother of the only male adolescent, suggested that his gender played a part in his low mood "there is an element of man up, being boys, you know" (Jenny). A number of mothers pointed to a perception of an increase in self-harming behaviour in schools and online, that "they are all doing it" (Sophie).

\section{Living with Uncertainty}

"Having a knot in your stomach the whole time, not quite knowing um, what's going to happen next" (Mel).

Self-harm and suicidal ideation was a major concern for all of the mothers who were interviewed and was associated with high anxiety and sense of unpredictability.

\section{Living with fear: "You are sort of on a, a knife edge really".}

Mel's use of the image of a knife edge is symbolic, as mothers' fears related primarily to attempts of self-harm or suicide. The majority of mothers described a constant worry about their child's mood and safety:

You wake up thinking about it and checking your phone in breaks at work and thinking is she alright (Emma).

Some mothers found it difficult to articulate their worries, "I worry that she is, you, is, that things could get worse, yeah for her" (Viv) and they struggled to clarify their precise fears, using expressions such as their child may do something "silly" (Alex) or "stupid" (Jenny) when referring to self-harm and suicidal behaviours. Participants sometimes alluded to the risks to their child's safety but were not explicit about their fears. Some mothers did express their fears more explicitly.

I didn't sleep, I'd doze off and I'd be awake every hour and I'd be wondering, worrying but you know, it's stupid things like is she going to be alive when I knock on her door in the morning (Viv).

The jarring juxtaposition of 'stupid things' and the concept that her child may not be alive highlights the difficulty mothers had verbalising, and perhaps acknowledging, these ideas, and the daily fear they experienced.

\section{Concerns about the long-term impact of depression: \\ "You're worrying about her future".}

In addition to their acute fears of self-harm and/or suicide a number of mothers expressed concerns about the longer term impact of depression on their child's education and future employment prospects. A few mothers referred to the possible trajectory and consequences of the depression.

She's not going to have motivation for anything, it's not just school, it's not just A levels, the slightest hurdle she hits with her plans to build her business are going to completely demotivate her again so she won't do anything (Viv).

I wouldn't want her to be diagnosed with something long-term either, bi-polar or sort of ... (trails off) (Jackie).

Here Jackie does not find the words to express what other long-term concerns could be, indicative of her anxiety about the future.

The unpredictability of the child's challenging behaviour: "It's like you're in a minefield and every so often you put your foot down wrong and it all blows up".

Alex compares living with a child with depression to living "in a minefield". The use of the metaphor of the violent and indiscriminate nature of a minefield underscores the mothers' inability to predict what may happen, and the potential destruction that may occur. It underlines the mothers' powerlessness to stop things from "blow(ing) up" with their child. 
Minefields are also associated with harming the innocent and the use of this metaphor may serve to highlight a sense of injustice felt by some mothers that they are in this situation. A number of mothers explained that every day was uncertain, they could not predict "what's she going to be like today" (Emma).

\section{Adapting parenting: "Walking on eggshells" (Jenny).}

In response to the uncertainty of their child's reactions, the majority of mothers described "tiptoeing around" (Viv) their child. This emphasised the fragility of their child's mood and the sense of inevitability that either challenging behaviour or low mood would be triggered. Mothers therefore consciously adapted their behaviour and felt they had to "watch what you do, you have to watch what you say" (Jenny). At times, the worry about their child's response led some mothers to adapt their parenting style, for example, to be less authoritarian about boundaries. "... not as perhaps confrontational about things as we would have been" (Jackie).

\section{Feelings of Helplessness and Frustration}

"You don't know what to do to make it better" (Viv).

All mothers in this sample described feeling distress linked to not knowing what they could do, or who they could rely on, to help their child. This sense of uncertainty left them with feelings of helplessness and frustration.

\section{Not knowing how to help.}

Alex provided a list of descriptors associated with a sense of uselessness, emphasising the extent of the feeling. "You also feel quite impotent or incompetent, helpless" (Alex). Jackie describe wanting "a manual and you could tick the boxes, done that, done that" (Jackie), which illustrated the structure, certainty and direction she felt she lacked.

Well, what do you do? What do you do? Where do we go with this? (Jane).

The use of rhetorical questions by mothers that were made throughout the interviews illustrates further a sense of uncertainty. Alex described the helplessness she felt, associated with wanting to reduce her child's distress and not having the ability to do so.
I think it's the feeling of helplessness which is the worst, you know, you want to make it better for them (Alex).

The expression "make it better" resonated with the general view that mothers felt they should be able to help their child and reduce their pain, and it is interesting to reflect on how this shared assumption may have contributed to the distress that mothers demonstrated during the interviews. Jane reported various ways of managing the situation but concluded that none of these were effective.

Then I kind of changed the approach and tried to push a bit more and in certain areas and then that didn't seem to be working and then, so you know, so I don't know, I don't know what the best way is, you know (Jane).

Jane was very articulate throughout the interview, but here she found it hard to put her experience into words, which may have highlighted her lack of confidence in how to manage.

\section{Not knowing who can help.}

The majority of mothers described needing to share the responsibility of supporting their child, to have it "registered somewhere" (Melanie). Jackie felt that she needed "additional support" because managing the difficulty was "out of my skill base as her Mum". Most were frustrated with the "huge lack of support" (Jenny) and understanding from others, and some were concerned that "resources are limited" (Mel) for young people with depression. For two mothers, frustration related to a lack of input and understanding from the child's father; the lack of support external to the family from school and the GP was also frustrating.

It's been frustrating with her Dad as well because he doesn't get any of it (Emma).

The lack of support from school has been really shocking (Sophie).

I wish I had the words without being rude just to say "come on put yourself in her shoes" and listen, take it seriously (Emma).

Emma's use of the phrase 'come on' exemplifies her feelings of frustration and the desire to confront the GP. Others felt that professionals did not fully understand their experiences. 
Yes they understand the textbook version but you don't actually understand living it which is totally different (Jenny).

\section{Depression Causes Change}

'Where's my daughter gone because that's not her' (Viv).

The fourth superordinate theme captures mothers' experiences that depression had caused a change in their child, and hence their relationships with them and their wider family.

\section{Loss of connection with child}

All the mothers in this sample noticed that their relationship with their child had changed. Jackie suggested that "there are times when you don't feel you can reach her". For a number of mothers this was a negative change in their relationship and communication, and they experienced a sense of loss. Typically, they felt more distant, for example that their children had "shut down" (Viv) or become "unreachable" (Mel). They felt unsure about their child's inner world and wanted to understand "what goes through [their] head" (Jenny).

She used to have these conversations with me [....] but then she just stopped talking (Viv).

I don't want her to sort of feel that she, what we had is gone, is lost, that was a childhood thing (Sophie).

It was noticeable that during the interviews mothers often became tearful when explaining this lack of communication, suggesting it was a particularly emotive aspect of the experience.

\section{Witnessing a change in personality: "loss of spirit"}

The mothers in this sample identified a marked difference in their child's personality following the onset of depression. They described the difference between how their child had been, for example, "a social bunny" (Jane) or "an absolute joy" (Viv) and how they currently could be, for example, a "horrible, horrible creature" (Alex). The change in the mothers' emotion when describing how their children used to be was apparent when they became animated and enthusiastic, in contrast to their demeanour when describing their child at the present time. Mothers described hope for recovery and positivity when their child at times displayed their previous personalities and behaviours; when they got to see their "daughter again" (Alex).

\section{Change in family interactions}

Some mothers also grieved a loss of how things had been before their child developed depression, and described a change in family life. This frequently was indicated by a reduction in the time the young person and mother spent together in shared activities.

I mean we did have quite a lot of family time, we'd sit and watch programmes together, now we have lots of stuff that's recorded on the Skybox (Viv).

No longer wanting to participate in any family things (Sophie).

\section{Hiding Own Emotions and Needs}

All the participants described their own difficulties dealing with the impact of depression on their son or daughter. Mel stated that witnessing her daughter's experience of depression was "heart-breaking" (Mel). The majority of mothers adopted their child's anguish, for example Alex said "they're in pain so you feel the pain" (Alex). Although not all mothers explicitly made this link to their own mental state, the mothers' distress was evident throughout the interviews. Despite the significantly emotional experiences described, the mothers said that they felt they had to remain positive and to keep their emotions hidden and under control in order to help the situation.

Where's the bloody light at the end of the tunnel, you know, where is it, um but you know it's about having to keep positive (Jenny).

Here Jenny quickly restricts her expression of emotion with a reminder of how she feels she should behave, using "but" to correct herself.

You have to be really solid, I feel I have to be really compos mentis [..] I can't have a, a weak moment because I'm afraid that if I do that it will all just fall apart you know (Sophie). 
Sophie illustrates here that she felt responsible for holding it "all" together and this highlights the pivotal role she considers herself to hold. The image of everything "fall [ing] apart" is powerful, and is suggestive of the fragility of the situation and the potentially disastrous effect of a "weak moment"; highlighting the pressure experienced by these mothers. According to one, the impact of living with this pressure is "mentally exhausting and physically exhausting" (Sophie).

During the interview a number of the mothers became tearful. Their preference to "keep feelings inside" (Alex) was also demonstrated by their apologies to the researcher for crying and their attempts to hold back their sad feelings during the interview. There seemed to be parallels between the mothers' and children's coping styles, with mothers reporting that their children did not express their thoughts and feelings.

As well as subjugating their emotions, some mothers also put their health and wellbeing needs last, behind those of their child and their families.

If you're ill, you don't go to the Doctor, there's an element of things um putting whatever is concerning you to one side (Jenny).

\section{Discussion}

We used a semi-structured interview to elicit mothers' accounts of their experiences of life with an adolescent child who is depressed. Detailed IPA analysis resulted in five main themes: finding a reason, something to blame; living with uncertainty; feelings of helplessness and frustration; depression causes change; and hiding own emotions and needs. The results are discussed in relation to current theory, research and implications for clinical practice.

A first major theme to emerge from our study involved maternal attempts to find reasons or attribute blame for their adolescent child's depression. Mothers' search for something to blame often touched upon self-blame. These observations concur with wider evidence that parents of children with a range of mental health difficulties commonly look for reasons 'why' their child is distressed (e.g. Thomson et al. 2014), and that maternal guilt is an important and common phenomenon in such contexts (Harden 2005; Stapley et al. 2015). This parental search for meaning can be seen not just as a desire to understand the specific experience, but as an existential question about 'why did this happen to us?' (Hatfield 1987, p.74). Interestingly, searching for meaning is also a key theme reported in qualitative studies exploring adolescents' own experiences of depression (Mccann et al. 2012), suggesting there may be some parallels between the experience of mothers and their children. Notably, this desire to make sense of a difficult experience may equate to ruminative thinking in some cases, with potentially negative consequences for the parents' own mood. Addressing concerns about the origins of depressive disorder through psychoeducation, when the range of factors known to contribute to depression and the prevalence of the difficulty in the population may be discussed, may serve to reduce feelings of maternal guilt.

The second theme we identified encapsulated the mothers' sense that their child's behaviour and the situation were unpredictable and potentially dangerous, and hence anxiety-provoking. High levels of worry about the risk of their child attempting suicide and/or self-harm in particular are consistent with the actual high rates of suicidal ideation and self-harm reported by young people with depression (Orchard et al. 2017).

Mothers expressed concerns that their own responses may trigger challenging or concerning behaviours in their child. The idea that mothers were 'walking on eggshells' was echoed in previous qualitative work, which indicated that parents of depressed adolescents experience distress, worry and anxiety (Stapley et al. 2015). Lefley (1996) suggests that parents regularly restrict setting boundaries and attempt to continually soothe their child, noting that parental responses and interactions with their child can change as a result of the presence of emotional difficulties in the child. Schwartz et al. (2011) identified that maternal responses to adolescent behaviour were predictive of later onset of depression in adolescents. The potential bidirectionality and timing of behaviour and mood between adolescent and parent may be a potentially fruitful area for further examination. Working to address the parental concerns may be one route to helping parents develop their sense of confidence in responding to their adolescent's distress.

Mothers in our study reported considerable feelings of helplessness and powerlessness. Stapley et al. (2015) found similar themes in their interviews, with parents reporting emotional turmoil and in particular feelings of helplessness. Additionally, our sample reported predominantly negative experiences of help-seeking for their child's mental health problem, which has been associated with increased experienced burden (Lefley 1996), and identified as a barrier to treatment and engagement (Rothì and Leavey 2006). A lack of knowledge about how to manage their child's difficulties, paired with a belief that they do not have access to adequate support, may have a negative impact on their child's wellbeing and recovery due to non-engagement with supportive networks. In the current mental health context in the UK, young people frequently do not have their treatment needs met within an optimal timeframe (e.g. Ford et al. 2007). Our 
findings highlight the potential for secondary impacts of such difficulties in treatment access for parents, in engendering feelings of hopelessness, which may have negative consequences for future treatment seeking and parental support for their child more broadly.

A further theme identified in the current study captured mothers' experiences of a significant change in their relationship with their child, in their child's personality, and in family life. This change in relationship in the current study with mothers was echoed in a previous qualitative study with parents of depressed adolescents, where a breakdown in communication between parents and adolescents was identified (Stapley et al. 2015). Relationships and communication are commonly renegotiated during adolescence (Keijsers and Poulin 2013), therefore these changes may have implications for the achievement of key developmental tasks (Rudolph et al. 2008). The change in parent-child communication may also reflect the interaction and communication problems associated with being a parent to someone with a mental health problem, and is in line with previous findings with other populations (Milliken and Northcott 2003; Oldershaw et al. 2008). This theme lends some support to an interpersonal theory of depression (Rudolph et al. 2008), which suggests that withdrawal can negatively impact social relationships by evoking negative affect in others, and can lead to increased interpersonal stress and thereby play a role in the maintenance of the depression. The theme also supports behavioural theories of depression, whereby depression is maintained by a reduction in positive reinforcement in the person's environment (Lewinsohn 1974).

The reported feelings of a sense of loss when parents observe changes in their child resonates with research on the parental experience of adolescent self-harm. Oldershaw et al. (2008) found that parents experienced two types of bereavement, one for the loss of their 'well' child, and another for 'what could have been'. Lefley (1997) similarly identified this 'dual loss' in her review of research on experiences of caregivers of adults with mental health difficulties. However, the results of the current study differed somewhat from those exploring experiences of mental health difficulties in an adult loved-one (e.g. Karp and Tanarugsachock 2000), as it found that mothers perceived that the change was temporary, that there were moments when the child 'returns'. This is an important finding since it suggests more of a hopeful outlook for the future by parents and one that perhaps could be expanded on in clinical practice with families where a child has depression.

A final theme described the mothers' sense that they should subjugate their own emotional experience. Even when experiencing high levels of distress, some mothers felt they were obliged to imply they were "fine". This is of concern as maternal distress has been shown to impact negatively on parent-child relationships and parenting approaches (De Coster and Cornell Zito 2013). This may reflect societal beliefs and expectations that a mother should put her child first and cope with challenges. It may also offer a way to minimise distress during the interviews or on behalf of the interviewer (Harden 2005). It is also possible that the mothers' tendency to subjugate their own needs and distress is related to their descriptions and experiences of self-blame. The mothers' projection of positivity despite their emotional experience, lends some support to the 'suppression of negativity mechanism' whereby parents subdue their own aggression or dysphoria in response to their child's dysphoric behaviour, which is proposed to maintain the depression (Schwartz et al. 2011). This theme has some similarities to the subordinate theme of parents 'denying own needs' identified in relation to self-harm (Oldershaw et al. 2008). However, in the present study the emphasis was on minimising feelings as well as their more practical needs. Subjugating one's own emotional and support needs, and a lack of self-care is of concern as it is associated with poorer mental and physical health outcomes and caregiver burnout (Lefley 1996).

Our study has a number of strengths. The interview accounts were analysed using IPA to identify the meaning of this lived experience to these mothers. The rationale for this detailed investigation was based on the centrality of the role mothers play as caregivers to their adolescent sons or daughters and as enablers and supporter of their children's access to treatment for depression. The research was grounded in a routine clinical service which gives the results good ecological validity. In line with an IPA approach, the study attempted to recruit a group of mothers of depressed adolescents who all shared a recent experience. Structured clinical interviews were used to diagnose depression in the adolescents. Mothers who took part were all recruited and interviewed at a comparable stage, shortly after diagnosis.

\section{Limitations}

It is important to note the limitations of our study. Individual interviews and data analysis are vulnerable to social desirability effects and to the implicit bias of researchers and participants. This was mitigated in several ways and a number of safeguards were included to increase the trustworthiness of the data. Mothers were recruited sequentially as they came into contact with CAMHs, therefore despite sharing the current experience of caring for a clinically depressed teen, in some demographic variables there was also a range of parenting circumstances (i.e. single parenthood and co-parenting) and some adolescents had multiple diagnoses, including one child who had mild cerebral palsy. 
To reduce the impact of this heterogeneity of diagnoses mothers were asked to refer to their experience of the depression as much as possible, and were given prompts when needed. Furthermore, seven of the mothers had daughters and only one had a son with depression. Data from qualitative research does not seek to be generalisable and the results cannot be assumed to apply to other mothers of depressed young people (Smith et al. 2009). However, as the data were collected using a flexible structured interview schedule and in-depth analysis was conducted, it provided rich and detailed data about these mothers' experiences.

The negative impact of adolescent depression on the mothers in this sample, as well as other previous research highlighting the burden on parents in a caring role, suggests that these individuals may benefit from support in their own right. This may be of significant importance given that parental wellbeing has been consistently shown to influence child and family outcomes (Early et al. 2002). This could be through professional support, or there may also be a useful role for parental peer support; sharing mental health caregiving experiences with others can also reduce the sense of burden (Cook et al. 1999). We are not aware of any studies that have examined the level of parent support that is provided within CAMHS services, but generally there are no formal guidelines about how to support parents when a child is experiencing depression. The level and type of support available to parents will be wholly dependent on the processes within local health services, as well as the availability of voluntary and other local services. Participants reported that it was difficult to share or express negative emotions to their child or in the family context, thus individual or group support could allow this expression in a safe environment. Given that parents reported the difficulty to attending to their own emotional needs, it may be important for clinicians to proactively offer this type of support. This would allow parents to have the space in order to think about how they could 'look after themselves in order to be able to look after their child'. It may also highlight important ways that mothers can model a self-care approach to their children.

Mothers frequently talked of wanting to understand why their child became depressed. Providing parents, as well as their child, with psychoeducation about the complexity in the development of depression and highlighting a range of risk factors other than family factors alone, may also help parents to make sense of 'where it came from' and possibly to counteract ideas that it is their fault and feelings of selfblame. Furthermore, information on depression symptoms and management of risk and self-harm should also be provided to parents. This has the potential to reduce feelings of powerlessness and to provide useful practical information. In addition to information, mothers in this study reported feeling helpless; thus any intervention could usefully incorporate methods to enhance parental self-efficacy by highlighting their existing strengths and capabilities (e.g. Asarnow et al. 2002).

Our study findings point to the changes in communication and interactions, which occurred for these mothers and their children. These issues were also found in previous studies (Stapely et al. 2015). Therapies which target improved family communication, such as family therapy or additional family components alongside individual CBT may be beneficial throughout treatment for adolescent depression (Dallos and Draper 2010; Larner 2009). However, the insight that mothers feel considerable guilt and blame for their child's difficulties suggests that clinicians should explain the role of family involvement in therapy, given that family therapy can be perceived as enforcing views that the family are to blame (Lefley 1996). Importantly, Lefley (1996) calls for clinicians to be more reflective about the assumptions they themselves may hold about parental blame to ensure they are amended.

The prominence of social narratives on mothers' responsibilities and the development of guilt in relation to these, as illustrated in this study, highlights the importance that these are considered in therapeutic work with families. A discussion about social and cultural expectations and their potential contribution to feelings of guilt and shame may be beneficial (Dallos and Draper 2010). Ideas from therapeutic approaches, which focus on shame may be helpful for some mothers, for example, compassion focused therapy (e.g. Gilbert 2010).

The inadequacy of support highlighted in this study suggests that mothers may be unclear about local support services. It may be that those in primary mental health care or education may benefit from further training or resources to allow them to respond to young people presenting with mental health difficulties and to consider parents in their assessments. Stapley et al. (2017) identified three distinct patterns of parental experiences of their adolescent's journey through CAMHS services, and suggested that services need to adapt their working approaches with families in order to support these parents in the most appropriate ways. Clinicians and service managers need to work towards providing clear guidance and timely care for young people as per government guidelines (Department of Health 2015). This is particularly important given that early intervention is associated with better outcomes for young people (Rothì and Leavey 2006).

Our qualitative data suggests a number of avenues in which further research may be useful. Firstly, it would be helpful to use the findings from this study to design and pilot a questionnaire with a large sample of parents of depressed adolescents to further investigate the experiences and challenges that these parents face and to perhaps compare these to a group of parents of children with no 
mood difficulties. Secondly, it seems important to investigate the type and format of information and support that parents would use and would find helpful (Oldershaw et al. 2008). Further research could be conducted to specifically consider enhancing parental coping when parenting a depressed child, potentially by comparing two treatment approaches, one treatment as usual, the other treatment with an additional parent support intervention.

There remains a need for an exploration of fathers' experiences of this phenomenon. This is particularly important given that a lack of paternal psychological wellbeing has been consistently linked with behavioural and emotional difficulties in their children (Ramchandani and Psychogiou 2009). Equally, mothers were predominantly White British so there were limited insights from other ethnic/ cultural groups so research in this area would be of value, particularly as evidence suggests that cultural differences exist in the understanding of, and help-seeking for depression (Cauce et al. 2002). As suggested above, a questionnaire-based study based on the identified themes in this study could be conducted with a large population of both mothers and fathers to further understand parental experiences.

The suggestion that some of the mothers' experiences reflected similar processes in their children is a valuable direction for future qualitative studies. This could be achieved by having parent-child dyads as participants and would allow for further exploration of this experience, and may have implications for processes of recovery. Furthermore, the current findings now provide scope for the development of further studies exploring specific aspects of the experience, such as the experience of guilt and shame, and how they manifest and impact on wellbeing.

This study considered mothers' experience at a specific point in their journey of having a child with depression, prior to intervention, and it may be interesting to further build on novel areas of work (e.g. Stapely et al. 2017) and consider how this experience develops over time using a longitudinal methodology, particularly in relation to experiences of services or therapy. A useful addition to the existing literature may be the development of a theory or model of this experience from the parental viewpoint, which would point to further research and intervention efforts.

\footnotetext{
Acknowledgements We wish to thank the families in this study for their time and personal accounts of their experiences. This study was conducted in part fulfilment of the first author's doctorate in clinical psychology whilst studying at University of Oxford. This report is independent research supported by the National Institute for Health Research for the second author (NIHR Doctoral Research Fellowship, M.P., DRF-2015-08-180). The views expressed in the publication are those of the authors and not necessarily those of the NHS, the NIHR or the Department of Health.
}

Author Contributions S.A.: designed and executed the study, analysed the data, and wrote the paper. M.P.: collaborated with the design, supervision, analysis and writing of the study. S.H. and S.R.: collaborated in the writing and editing of the final manuscript.

\section{Compliance with Ethical Standards}

Conflict of Interest The authors declare that they have no conflict of interest.

Ethical Approval Ethical approval for the study was granted by the Research Sub-Committee of the Oxford Doctoral Course in Clinical Psychology, Oxford University, and the South Central NHS-Berkshire B Research Ethics Committee (13/SC/0485).

Informed Consent Informed written consent for the study was obtained from all the mothers and assent (for their mothers to participate) was obtained from the adolescents.

Publisher's note Springer Nature remains neutral with regard to jurisdictional claims in published maps and institutional affiliations.

Open Access This article is licensed under a Creative Commons Attribution 4.0 International License, which permits use, sharing, adaptation, distribution and reproduction in any medium or format, as long as you give appropriate credit to the original author(s) and the source, provide a link to the Creative Commons license, and indicate if changes were made. The images or other third party material in this article are included in the article's Creative Commons license, unless indicated otherwise in a credit line to the material. If material is not included in the article's Creative Commons license and your intended use is not permitted by statutory regulation or exceeds the permitted use, you will need to obtain permission directly from the copyright holder. To view a copy of this license, visit http://creativecommons. org/licenses/by/4.0/.

\section{References}

Asarnow, J. R., Scott, C. V., \& Mintz, J. (2002). A combined cognitivebehavioral family education intervention for depression in children: a treatment development study. Cognitive Therapy and Research, 26, 221-229. https://doi.org/10.1023/A:1014573803928.

Cauce, A., Domenech-Rodriguez, M., Paradise, M., Cochran, B., Shea, J., Srebnik, D., \& Baydar, N. (2002). Cultural and contextual influences in mental health help seeking: a focus on ethnic minority youth. Journal of Consulting and Clinical Psychology, 70, 44-55. https://doi.org/10.1037/0022-006X.70.1.44.

Cook, J. A., Heller, T., \& Pickett-Schenk, S. A. (1999). The effect of support group participation on caregiver burden among parents of adult offspring with severe mental illness. Family Relations: An Interdisciplinary Journal of Applied Family Studies, 48, 405-410. https://doi.org/10.2307/585248.

Dallos, R., \& Draper, R. (2010). An introduction to family therapy: systemic theory and practice. 3rd ed. Berkshire, England: Open University Press.

De Coster, S., \& Cornell Zito, R. (2013). Maternal roles and adolescent depression: conditions and processes of influence. Sociological Perspectives, 56, 1-23. https://doi.org/10.1525/sop.2012. 56.1.1.

Deater-Deckard, K. (2004). Parenting stress. London, England: Yale University Press.

Department of Health. (2015). Future in mind: promoting, protecting and improving our children and young people's mental health and wellbeing. London, England: NHS England. 
Diamond, G. S., Wintersteen, M. B., Brown, G. K., Diamond, G. M., Gallop, R., Shelef, K., \& Levy, S. (2010). Attachment-based family therapy for adolescents with suicidal ideation: a randomized controlled trial. Journal of the American Academy of Child and Adolescent Psychiatry, 49, 122-31.

Draucker, C. B. (2005). Interaction patterns of adolescents with depression and the important adults in their lives. Qualitative Health Research, 15, 942-963. https://doi.org/10.1177/ 1049732305277859 .

Early, T., Gregoire, T., \& McDonald, T. (2002). Child functioning and caregiver well-being in families of children with emotional disorders: a longitudinal analysis. Journal of Family Issues, 23, 374-391. https://doi.org/10.1177/0192513×02023003003.

Fergusson, D. M., \& Woodward, L. J. (2002). Mental health, educational, and social role outcomes of adolescents with depression. Archives of General Psychiatry, 59, 225-231. https://doi.org/10. 1001/archpsyc.59.3.225.

Ford, T., Hamiltion, H., Meltzer, H., \& Goodman, R. (2007). Predictors of serice use for mental health problems among british schoolchildren. Child and Adolescent Mental Health, 13, 32-40. https://doi.org/10.1111/j.1475-3588.2007.0049.x.

Garber, J. (2005). Depression and the family. In J. L. Hudson \& R. M. Rapee (Eds.), Psychopathology and the family (pp. 227-283). Oxford, England: Elsevier.

Gilbert, P. (2010). The compassionate mind. London, England: Constable \& Robinson Ltd.

Glied, S., \& Pine, D. S. (2002). Consequences and correlates of adolescent depresssion. Archives of Pediatrics \& Adolescent Medicine, 156, 1009-1014. https://doi.org/10.1001/archpedi.156. 10.1009 .

Goodyer, I. M., Reynolds, S., Barrett, B., Byford, S., Dubicka, B., Hill, J., \& Fonagy, P. (2017). Cognitive behavioural therapy and short term psychoanalytical psychotherapy versus a brief psychosocial intervention in adolescents with unipolar major depressive disorder (IMPACT): a multicentre, pragmatic, observer-blind, randomised controlled superiority trial. The Lancet Psychiatry, 4, 109-119. https://doi.org/10.1016/S2215-0366(16) 30378-9.

Gryglewicz, K., Kutash, K., Elzy, M. B., Hangartner, R. R., \& Karver, M. S. (2018). Engaging families: a pilot evaluation to examine the utility of a health promotional resource on youth suicide prevention. Journal of Family Social Work, 21, 399-412. https:// doi.org/10.1080/10522158.2018.1469560.

Harden, J. (2005). "Uncharted Waters": the experience of parents of young people with mental health problems. Qualitative Health Research, 15, 207-223. https://doi.org/10.1177/1049732304269677.

Hatfield, A. B. (1987). Coping and adaptation: a conceptual framework for understanding families. In A. B. Hatfield \& H. P. Lefley (Eds.), Families of the mentally ill: coping and adaptation (pp. 60-84). London: Cassell.

Hurley, A. D. (2008). Depression in adults with intellectual disability: symptoms and challenging behaviour. Journal of Intellectual Disability Research, 52, 905-916. https://doi.org/10.1111/j.13652788.2008.01113.x.

Karp, D. A., \& Tanarugsachock, V. (2000). Mental illness, caregiving, and emotion management. Qualitative Health Research, 10, 6-25. https://doi.org/10.1177/104973200129118219.

Keijsers, L., \& Poulin, F. (2013). Developmental changes in parent-child communication throughout adolescence. Developmental Psychology, 49, 2301-2308. https://doi.org/10.1037/a 0032217.

Larner, G. (2009). Integrating family therapy in adolescent depression: an ethical stance. Journal of Family Therapy, 31, 213-232. https://doi.org/10.1111/j.1467-6427.2009.00468.x.

Larkin, M., Watts, S., \& Clifton, E. (2006). Giving voice and making sense in interpretative phenomenological analysis. Qualitative
Research in Psychology, 3, 102-120. https://doi.org/10.1191/ 1478088706qp062oa.

Lefley, H. P. (1996). Family caregiving in mental illness. London, England: Sage Publications.

Lefley, H. P. (1997). Synthesizing the family caregiving studies: Implications for service planning, social policy, and further research. Family Relations, 46, 443-450. https://doi.org/10.2307/ 585104.

Lewinsohn, P. M. (1974). A behavioural approach to depression. In R. J. Friedman \& M. M. Katz (Eds.), Psychology of depression: contemporary theory and research (pp. 157-178). Oxford: Wiley.

Mccann, T. V., Lubman, D. I., \& Clark, E. (2012). The experience of young people with depression: a qualitative study. Journal of Psychiatric and Mental Health Nursing, 19, 334-340. https://doi. org/10.1111/j.1365-2850.2011.01783.x.

Midgley, N., Parkinson, S., Holmes, J., Stapley, E., Eatough, V., \& Target, M. (2015). Beyond a diagnosis: the experience of depression among clinically-referred adolescents. Journal of Adolescence, 44, 269-279.

Nock, M. K., \& Ferriter, C. (2005). Parent management of attendance and adherence in child and adolescent therapy: a conceptual and empirical review. Clinical Child and Family Psychology Review, 8, 149-166. https://doi.org/10.1007/s10567-005-4753-0.

Milliken, P. J., \& Northcott, H. C. (2003). Redefining parental identity: caregiving and schizophrenia. Qualitative Health Research, 13, 100-113. https://doi.org/10.1177/1049732302239413.

Oldershaw, A., Richards, C., Simic, M., \& Schmidt, U. (2008). Parents' perspectives on adolescent self-harm: qualitative study. British Journal of Psychiatry, 193, 140-144. https://doi.org/10. 1192/bjp.bp.107.045930.

Orchard, F., Pass, L., Marshall, T., \& Reynolds, S. (2017). Clinical characteristics of adolescents refered for treatment of depressive disorders. Child and Adolescent Depression, 22, 61-68. https:// doi.org/10.1111/camh.12178.

Page, J, Whitting, G., \& Mclean, C. (2008). A review of how fathers can be better recognised and supported through DCSF policy. Nottingham, England: Department for Children, Schools and Families. http://dera.ioe.ac.uk/8562/1/DCSF-RR040.pdf.

Polanczyk, G. V., Salum, G. A., Sugaya, L. S., Caye, A., \& Rohde, L. A. (2015). Annual research review: a meta-analysis of the worldwide prevalence of mental disorders in children and adolescents. Journal of Child Psychology and Psychiatry, 56, 345-365. https://doi.org/10.1111/jcpp.12381.

Puig-Antich, J., \& Chambers, W. (1978). The schedule for affective disorders and schizophrenia for school-age children (Kiddie$S A D S)$. New York, NY: Psychiatric Institute.

Ramchandani, P., \& Psychogiou, L. (2009). Paternal psychiatric disorders and children's psychosocial development. Lancet, 374, 646-653. https://doi.org/10.1016/S0140-6736(09)60238-5.

Raphael, H., Clarke, G., \& Kumar, S. (2006). Exploring parents' responses to their child's deliberate self harm. Health Education, 106, 9-20. https://doi.org/10.1108/09654280610637166.

Rothì, D. M., \& Leavey, G. (2006). Mental health help-seeking and young people: a review. Pastoral Care in Education, 24, 4-13. https://doi.org/10.1111/j.1468-0122.2006.00373.x.

Rudolph, K. M., Flynn, M., \& Abaied, J. L. (2008). A developmental perspective on interpersonal theories of youth depresssion. In J. R. Z. Abela \& B. L. Hankin (Eds.), Handbook of depression in children and adolescents (pp. 79-102). New York, NY: Guildford.

Schwartz, O. S., Dudgeon, P., Sheeber, L. B., Yap, M. B., Simmons, J. G., \& Allen, N. B. (2011). Observed maternal responses to adolescent behaviour predict the onset of major depression. Behaviour Research and Therapy, 49, 331-338. https://doi.org/ 10.1016/j.brat.2011.02.008. 
Shaw, S. K., Dallos, R., \& Shoebridge, P. (2009). Depression in female adolescents: an IPA analysis. Clinical Child Psychology and Psychiatry, 14, 167-181. https://doi.org/10.1177/ 135910450810088219293317.

Sheeber, L. B., Johnston, C., Chen, M., Leve, C., Hops, H., \& Davis, B. (2009). Mothers' and fathers' attributions for adolescent behavior: an examination in families of depressed, subdiagnostic, and nondepressed youth. Journal of Family Psychology, 23, 871-881. https://doi.org/10.1037/a001675820001146.

Smith, J. A. (1996). Beyond the divide between cognition and discourse: Using interpretative phenomenological analysis in health psychology. Psychology \& Health, 11, 261-271. https://doi.org/ 10.1080/08870449608400256.

Smith, J. A., Larkin, M. H., \& Flowers, P. (2009). Interpretative phenomenological analysis: theory, method and research. London: SAGE.

Stapley, E., Midgley, N., \& Target, M. (2015). The experience of being the parent of an adolescent with a diagnosis of depression. Journal of Child and Family Studies, 25(2), 618-630. https://doi. org/10.1007/s10826-015-0237-0.

Stapley, E., Midgley, N., \& Target, M. (2017). The journey through and beyond mental health services in the United Kingdom: a typology of parents' ways of managing the crisis of their teenage child's depression. Journal of Clinical Psychology, 73(10), 1429-1441. https://doi.org/10.1002/jclp.22446.

Steca, P., Bassi, M., Caprara, G. V., \& Fave, A. D. (2011). Parents' self-efficacy beliefs and their children's psychosocial adaptation during adolescence. Journal of Youth and Adolescence, 40, 320-331. https://doi.org/10.1007/s10964-010-9514-920 204688.
Stewart, M. E., Barnard, L., Pearson, J., Hasan, R., \& O’Brien, G. (2006). Presentation of depression in autism and Asperger syndrome: a review. Autism, 10, 103-116. https://doi.org/10.1177/ 1362361306062013.

Tan, S., \& Rey, J. (2005). Depression in the young, parental depression and parenting stress. Australasian Psychiatry, 13, 76-79. https://doi.org/10.1080/j.1440-1665.2004.02155.x.

Thomson, S., Marriott, M., Telford, K., Law, H., McLaughlin, J., \& Sayal, K. (2014). Adolescents with a diagnosis of anorexia nervosa: Parents' experience of recognition and deciding to seek help. Clinical Child Psychology and Psychiatry, 19, 43-57. https://doi.org/10.1177/1359104512465741.

Wells, K. C., \& Albano, A. M. (2005). Parent involvement in CBT treatment of adolescent depression: experiences in the treatment for adolescents with depression study (TADS). Cognitive and Behavioral Practice, 12, 209-220. https://doi.org/10.1016/ S1077-7229(05)80026-4.

Willig, C. (2008). Introducing qualitative research methods in psychology. Maidenhead, England: McGraw Hill/Open University Press.

Zisook, S., Rush, A. J., Lesser, I., Wisniewski, S. R., Trivedi, M., Husain, M. M., \& Fava, M. (2007). Preadult onset vs. adult onset of major depressive disorder: a replication study. Acta Psychiatrica Scandinavica, 115, 196-205. https://doi.org/10.1111/j. 1600-0447.2006.00868.x.

Zwaanswijk, M., Van Der Ende, J., Verhaak, P. F. M., Bensing, J. M., \& Verhulst, F. C. (2005). Help-seeking for child psychopathology: pathways to informal and professional services in The Netherlands. Journal of the American Academy of Child and Adolescent Psychiatry, 44, 1292-1300. https://doi.org/10.1097/ 01.chi.0000181038.98712.c6. 